\title{
VANGUARDA, CARTAZ E CINEMA: UMA APROXIMAÇÃO ENTRE A ESCOLA POLONESA E SAUL BASS
}

Laila Rotter Schmidt

Centro Universitário da Fundação Assis Gurgacz

lailarsc@yahoo.com.br

Resumo: Este trabalho visa realizar uma leitura comparativa dos cartazes de cinema criados nas décadas de 1950 e 1960 pela Escola Polonesa em relação aos criados pelo designer norte americano Saul Bass no mesmo período, considerando que ambos realizaram uma notável ruptura com a linguagem visual estabelecida pelo cinema hollywoodiano na década de 20 . O principal objetivo deste estudo é investigar as condições e influências que conduziram à criação de cartazes igualmente inovadores e de estética semelhante, ainda que em contextos radicalmente distintos. Para isto será realizada uma aproximação buscando identificar pontos de contato e de distanciamento entre as obras, seus autores e contextos de produção, visando contribuir com o estudo do design de vanguarda, em especial no âmbito dos cartazes de cinema.

Palavras-chave: Design gráfico, Cartazes de cinema, Vanguarda, Escola Polonesa de Cartaz, Saul Bass.

Abstract: The present essay aims to compare cinema posters created on the 1950's and 1960's by the Polish Poster School and by the north american designer Saul Bass. Considering that both realized a considerable break towards common language stablished by Hollywood cinema on the 1920's, the main objective of the essay is to investigate the conditions and influences that lead the Polish artists and Saul Bass to create such an innovative and similar language in comparison to one another, but in context radically different to one another. To accomplish such an objective the essay will identify common and distinct points among the posters, its authors and production contexts, contributing to the study of avant-garde design, specially in regard to cinema posters.

Keywords: Graphic design, Cinema posters, Avant-garde, Polish Poster School, Saul Bass. 


\section{INTRODUÇÃO}

Afixados frente às ruas movimentadas do início do século 20 , os cartazes eram tão populares para divulgar produtos, serviços e eventos que constituíram-se de um dos primeiros meios de comunicação em massa amplamente utilizados. Enquanto alguns cartazes destacaram-se por abordagens estéticas inovadoras em um contexto funcional, outros adquiriam status de obra de arte e serviram como meios de expressão e interpretação da realidade por designers e artistas.

Para Abraham Moles (2004, p. 29-32), a força da mensagem visual do cartaz está relacionada com a simplicidade da sua mensagem e seu apelo aos impulsos fundamentais do indivíduo. Ainda segundo o autor, ao evidenciar as influências históricas ou econômicas de um país, o cartaz é responsável pela consolidação de uma "cultura visual" sobre os muros da cidade.

Ainda que o primeiro cartaz conhecido remeta a 1860, Cardoso (2004, p. 48) esclarece que a consolidação deste, na forma como é conhecido atualmente, somente foi possível alguns anos depois. Foi o desenvolvimento dos meios de impressão, tais como a xilogravura e litografia, que viabilizaram a produção do cartaz em larga escala.

De acordo com Philip Meggs (2009, p. 250), foi uma mudança na legislação francesa a responsável pelo desenvolvimento da indústria de cartazes. $O$ autor explica que, a partir de 1881, tornou-se permitida a afixação de cartazes em praticamente todos os espaços urbanos, o que converteu as ruas em verdadeiras galerias de arte: "O movimento arts and crafts estava gerando um novo respeito pelas artes aplicadas, e Jules Chéret mostrou o caminho".

Considerado o "pai" do cartaz moderno, Jules Chéret forneceu os alicerces desta nova forma artística e funcional e realizou a transição da era vitoriana para o art nouveau. Já era possível observar nos seus cartazes dos anos 1890 a estrutura que se tornou característica do cartaz (Fig. 1), na qual texto e imagem são partes indissociáveis da mensagem. Moles (2004, p. 19) chamou-a de "imagem comentada", referindo-se ao sentido da imagem que se constrói pelo intermédio de um texto.

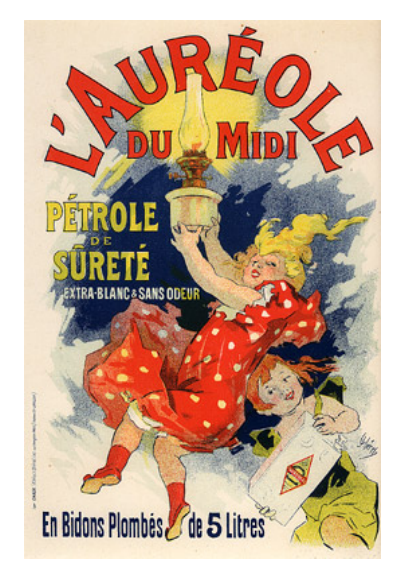

Figura 1 - Jules Cherét, cartaz, "L'aureole du midi", 1873. Fonte: MEGGS, 2009

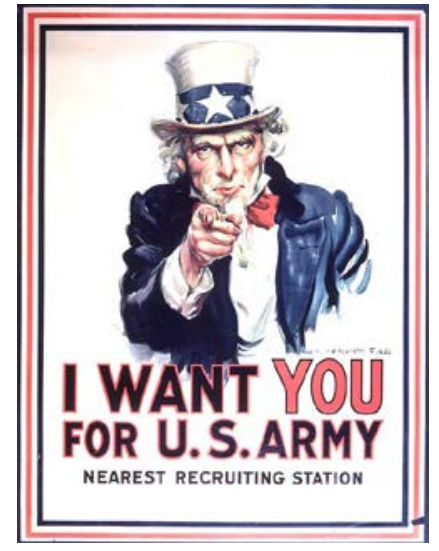

Figura 2 - James M. Flagg, cartaz de recrutamento, 1917. Fonte: MEGGS, 2009

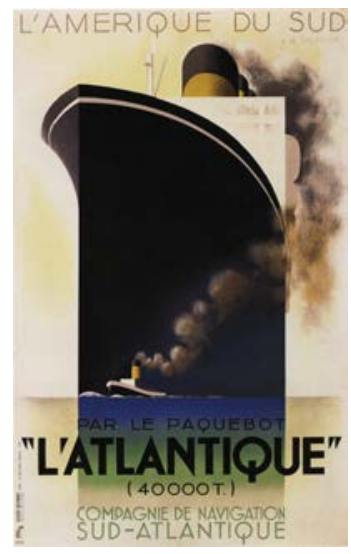

Figura 3-A. M. Cassandre, cartaz para o "L'Atlantique", 1931. Fonte: MEGGS, 2009

Durante a Primeira Guerra Mundial (1914-1918) o cartaz atingiu o auge da sua importância como meio de comunicação. Foi utilizado pelos governos como forma de 
propaganda e persuasão visual quando o rádio e outros meios de comunicação de massa não estavam plenamente difundidos (Fig. 2) (MEGGS, 2009, p. 351).

No período entre guerras o cartaz experimentou uma nova linguagem, muito influenciada pelos movimentos modernistas. Para Cardoso (2004, p. 130), esta fase "remete aos esforços de alguns dos grandes nomes contemporâneos do design de cartazes internacional como A. M. Cassandre, E. McKnight e Jean Carlu". De acordo com Meggs (2009, p. 362), Cassandre revitalizou a publicidade francesa com grande quantidade de cartazes compostos por expressões concisas. De forte influência cubista, seus cartazes reduziam temas a símbolos iconográficos evidenciando a bidimensionalidade por meio de formas geométricas e planos de cor chapados (Fig. 3). No mesmo sentido, Jean Carlu procurou transmitir a essência da mensagem visual evitando o uso de "duas linhas onde uma bastaria" (MEGGS, 2009, p. 363).

O período após a primeira guerra mundial foi marcado também pela consolidação da indústria do cinema nos Estados Unidos. O despontar de Hollywood como maior produtora mundial de filmes, com cerca de 800 títulos lançados anualmente, teve como consequência direta o aumento do número de cartazes produzidos com propósito de anunciar a exibição dos filmes (CARDOSO, 2004, p.124).

O cartaz era utilizado na divulgação de espetáculos de entretenimento quando surgiu o cinema. As primeiras obras dos irmãos Lumière já foram anunciadas por meio de cartazes que ilustravam a nova experiência de assistir um filme em uma sala de cinema. Historicamente o cartaz cumpriu um papel tão importante na divulgação de filmes que a expressão "em cartaz" se tornou sinônimo de "em exibição".

O estilo dos cartazes hollywoodianos do início do século 20 foi marcado por características próprias e muito distantes da vanguarda europeia. Os elementos básicos destes cartazes eram stills de cenas do filme, utilizados tanto individualmente quanto em conjunto, antecipando trechos do que o espectador iria encontrar no filme.

Em especial na década de 1920, em meio ao pleno desenvolvimento do star system, "as estrelas de Hollywood passaram a ditar mundialmente os padrões de comportamento e também de consumo que dominavam então a sociedade americana" (CARDOSO, 2004, p. 125). Como a imagem dos atores era o principal recurso de venda de um filme, os close-ups expressivos das estrelas eram o elemento central da composição dos cartazes. Sua função era tanto gerar interesse pela narrativa quanto identificar o gênero do filme.

Esta estética está intimamente relacionada ao caráter fortemente comercial do cartaz destinado à indústria do cinema. Hollywood investia quantidades exorbitantes na produção de suas obras e precisava obter retorno por meio de bilheterias expressivas. O cartaz, neste contexto, consistia em seu principal veículo de divulgação e venda. A fórmula do cartaz descritivo se demonstrou tão eficiente que se encontra em uso pelo cinema comercial até os dias de hoje.

No entanto, é possível encontrar na história do design momentos em que esta estética foi questionada e novas formas de expressar graficamente a essência de um filme foram exploradas. O cartaz de cinema apresenta o desafio particular de traduzir a complexidade da linguagem cinematográfica em uma mensagem concisa que convida o expectador a apreciá-la. Cumpre, assim, a importante função de transportar o filme para fora da sala de projeção e torná-lo alcançável a um piscar de olhos. Neste sentido, o designer encontra no cartaz a oportunidade de transcender a experiência 
meramente descritiva para proporcionar uma experiência provocativa ou para expressar um modo particular de olhar sobre o filme.

Ainda que no cinema de vanguarda experimentações na linguagem do cartaz tenham sido mais frequentes, como é o caso do expressionismo alemão e do construtivismo russo, também no contexto do cinema comercial norte-americano é possível apontar momentos de profundo rompimento com a estética hollywoodiana. Neste contexto destacam-se a Escola Polonesa de Cartaz dos anos 1950-60 e os cartazes do designer norte americano Saul Bass. Apesar de terem se desenvolvido em contextos muito diferentes, estes podem ser aproximados pela experimentação e inovação na linguagem de cartazes cinematográficos que propuseram.

A Escola Polonesa de Cartaz desenvolveu um estilo gráfico nacional distinto e reconhecível nas duas décadas que se seguiram à Segunda Guerra Mundial (19391945) (HOLLIS, 2000, p. 185). É reconhecida mundialmente por uma extensa produção de cartazes com abordagem conceitual e essencialmente artística.

Após a segunda guerra mundial, a Polônia devastada foi dominada pela União Soviética e teve o regime comunista implantado em seu território. Como muitos aspectos da vida social e cultura do país, a distribuição de filmes passou a ser controlada pelo governo, que comissionava artistas locais para criar os cartazes que anunciavam a exibição destes filmes (THOMAS et al., 2001, p. 7). De acordo com Hollis (2000, p. 186), só para o cinema eram produzidos mais de 200 cartazes por ano.

Henryk Tomaszewski, um dos mais importantes nomes da Escola Polonesa, explica que "como os cinemas eram escassos e quase sempre estavam lotados, o papel comercial do cartaz ficava em segundo plano" (Behind The Poster, 2010, tradução nossa). A liberação da função comercial significava liberação da obrigação de usar a imagem dos atores. De modo geral, os designers desfrutavam de extensa liberdade de criação, especialmente após a morte de Stalin em 1953 (ZIELINSKI, 1994, p. 34).

Dentre os filmes que ganharam cartazes poloneses, encontram-se inúmeros títulos norte-americanos. A abordagem dada a estes cartazes era completa e deliberadamente diferente dos padrões hollywoodianos, já que os designers consideravam o cartaz como uma forma de expressão artística (ZIELINSKI, 1994, p. 31).

A estética experimental dos cartazes poloneses fundia influências modernistas e tradição folclórica, de modo que cada artista desenvolveu um estilo próprio (HOLLIS, 2000, p. 185). Com frequência os cartazes se assemelhavam a pinturas, mas também incorporavam técnicas de colagem e fotomontagem (THOMAS et al., 2001, p. 9).

Da mesma forma que e Escola Polonesa de Cartaz operou uma ruptura com os códigos visuais estabelecidos para os cartazes de filmes, também o fez o designer norte americano Saul Bass (1920-1996). Reconhecido por ter realizado uma produtiva interseção entre a linguagem visual do cinema e do design gráfico, Bass revolucionou a criação de sequências iniciais e cartazes de filmes em Hollywood. Foi influenciado pelo trabalho de Cassandre e Moholy-Nagy e integrou o movimento conhecido como Escola de Nova lorque, que buscava solucionar problemas de comunicação, no contexto de uma sociedade altamente competitiva, e ao mesmo tempo satisfazer a necessidade de expressão pessoal dos designers (MEGGS, 2009, p. 486).

A sequência de abertura de The man with the golden arm (1955) marca uma nova era, na qual este elemento do filme, até então negligenciado, passou a ser responsável por atribuir identidade ao título, gerar expectativa, provocar curiosidade e preparar o público para a narrativa que viria a seguir. Os cartazes de Bass eram 
caracterizados pela abstração, minimalismo, pureza formal e simbolismo. Estas estratégias visuais eram adotadas pelo designer para captar a "essência" do filme e apresentá-la de forma provocativa, com o propósito de motivar o público a vê-lo. Aproximando-se da vanguarda, que recusa a imitação da aparência e busca construir sentidos a partir de uma expressão visual simbólica, Bass considerava o cartaz como parte de um projeto mais amplo de identidade visual que abarca outros elementos, entre eles a própria abertura do filme.

Partindo da ruptura com o padrão estético que a Escola Polonesa e os cartazes de cinema de Saul Bass têm em comum, este trabalho objetiva investigar possíveis aproximações e distanciamentos entre eles. Com isto, espera-se colaborar com a compreensão das condições que permitiram o desenvolvimento destas duas correntes que revolucionaram a comunicação visual no contexto do cinema.

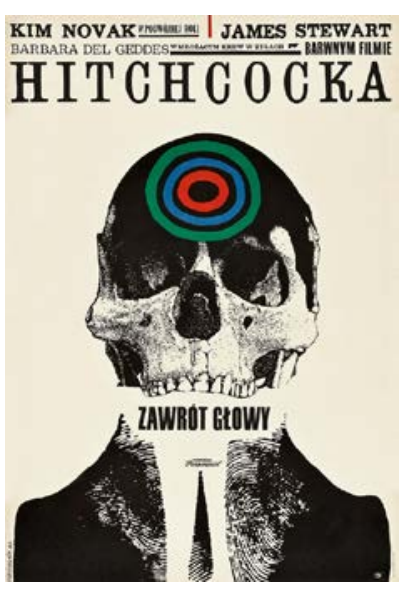

Figura 4 - Roman Cieslewicz, Cartaz de "Vertigo", 1963. Fonte: www.polishposters.com

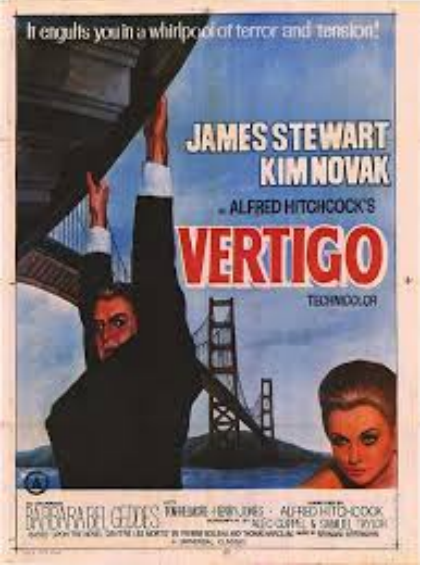

Figura 5 - Cartaz de "Vertigo". Fonte: www.mopopoc.com

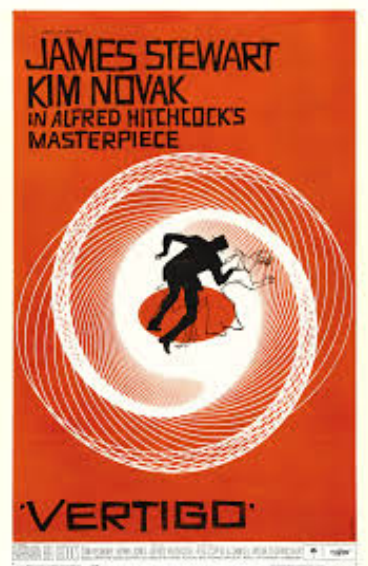

Figura 6 - Saul Bass, Cartaz de "Vertigo", 1963.

Fonte: BASS; KIRKHAM, 2011

\section{DESENVOLVIMENTO}

A fim de atingir os objetivos propostos, serão observados em seguida aspectos contextuais e estéticos dos cartazes de cinema produzidos por ambos.

\subsection{A escola polonesa}

Ao longo dos séculos a Polônia foi tomada por inúmeras invasões estrangeiras. Chegou a sumir do mapa antes de reconquistar sua soberania durante a Primeira Guerra Mundial. Antecedida por 20 anos de independência, a Segunda Guerra Mundial deixou o território polonês devastado e dominado pelo regime comunista. Apesar de seu destino trágico, a Polônia sempre lutou para preservar suas tradições culturais.

O desenvolvimento particular que o cartaz teve na Polônia está intimamente relacionado às mudanças que estavam ocorrendo na sua história desde o final do século 19, quando a dominação Austríaca concedeu maior autonomia ao país. Foi quando os primeiros cartazes poloneses, refletindo o estilo art nouveau preconizado por Jules Chéret, introduziram uma nova forma de comunicação e de arte.

O cartaz tornou-se tão popular na sociedade polonesa que em 1896 foi realizada a primeira Exposição Internacional do Cartaz em Cracóvia, cujo principal legado foi incorporar tendências modernistas e elementos tradicionais de simbolismo, 
iconografia e folclore da Polônia (MILLIE; KANTOROSINSKI, 1993, p. 1-4). "Esta forma artística era acessível a todos e havia um sentimento de identidade nacional associado à arte do cartaz no início do século 20" (THOMAS et al., 2001, p. 6, tradução nossa).

No período entre guerras as artes aplicadas se desenvolveram especialmente graças à arquitetos poloneses como Tadeusz Gronowski. O grupo de arquitetos se considerava parte do movimento mais amplo de arte e design conhecido como art déco e organizava viagens frequentes para a França, Itália, Tchecoslováquia, Holanda e Inglaterra (THOMAS et al., 2001, p. 6). Como consequência destes intercâmbios, estes arquitetos foram influenciados pelos movimentos artísticos de vanguarda como o cubismo, o futurismo, o construtivismo e o surrealismo. Neste período era frequente a realização de workshops especializados, exposições e competições voltadas à arte do cartaz (CZESTOCHOWSKI; FIJALKOWSKA, 1978, p 4).

A Segunda Guerra interrompeu abruptamente este ciclo ao deixar o país em ruínas e sob dominação soviética, mas não foi capaz de apagar a tradição do cartaz. Pelo contrário: o novo cenário político e cultural deu-lhe ainda mais ressonância. Neste trabalho vamos nos concentrar nos cartazes de filmes das décadas de 50 e 60, apesar de a Escola Polonesa ter produzido também cartazes informativos, para espetáculos de circo, teatro e ópera e também cartazes políticos até o final do comunismo em 1989.

O status que o cartaz polonês alcançou foi resultado do sistema comunista imposto na Polônia e da política de controle estatal que centralizou a distribuição dos filmes e da produção de cartazes de cinema (ZIELINSKI, 1994, p. 30). As instituições estatais procuraram uma rede de artistas e professores das escolas de artes para criar cartazes de promoção de eventos e distribuição de informação. Neste contexto se inseriam os cartazes dos filmes importados para exibição na Polônia. O núcleo da Escola Polonesa era composto inicialmente por Eyrk Lipiński, Henryk Tomaszewski e Tadeusz Trepkowski. Posteriormente, fizeram parte também Jan Lenica, Wiktor Górka, Roman Cieślewicz e Waldemar Świerzy, entre outros (THOMAS et al., 2001, p. 8).

Estes artistas consideravam o cartaz um objeto artístico e desejavam utilizá-lo como forma de expressão de uma visão pessoal. No documentário Freedom on the Fence (2012) Tomaszewski conta que o departamento de propaganda recebia cartazes norte-americanos junto com os filmes a serem distribuídos, mas, como estes eram escritos em inglês, não podiam ser utilizados. Quando aceitou o convite para criar os novos cartazes, em consenso com seus colegas, ele deixou claro que "o faria com uma condição: que não se esperasse deles fazer algo parecido com os cartazes originais, e que eles teriam liberdade para criar os cartazes do seu próprio jeito" (Freedom on the Fence, 2012, tradução nossa).

Uma vez que a distribuição dos filmes não estava sujeita à pressão das bilheterias, a liberdade desejada pôde ser concedida, e o artista de cartaz passou a substituir o protagonista do filme como "herói". Havia muita controvérsia na época sobre o fato de que muitas vezes o tamanho da assinatura do artista estava na mesma proporção do nome do ator ou atriz principal. Normalmente os cartazes não tinham nem detalhes específicos dos eventos, tais como locais e horários, já que as pessoas iam regularmente ao cinema local e teatro (THOMAS et al., 2001, p. 7).

Os cartazes eram frequentemente colados nos tapumes que cercavam os edifícios que aguardavam a reconstrução pós-guerra, fazendo das ruas galerias onde os trabalhos dos artistas podiam ser vistos (THOMAS et al., 2001, p. 8). Em entrevista para o documentário Behind de Poster (2010, tradução nossa) Świerzy conta que "os 


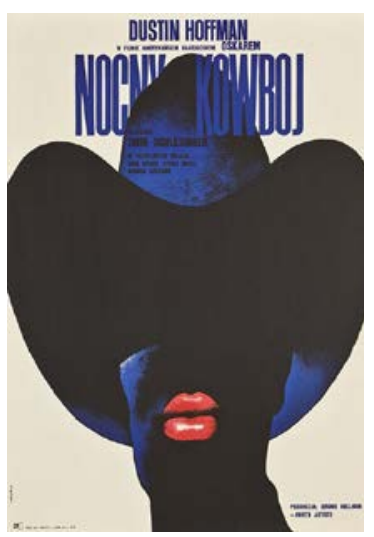

Figura 7 - Waldemar Świerzy, Cartaz de "Midnight Cowboy", 1969. Fonte: www.po lishposter.com

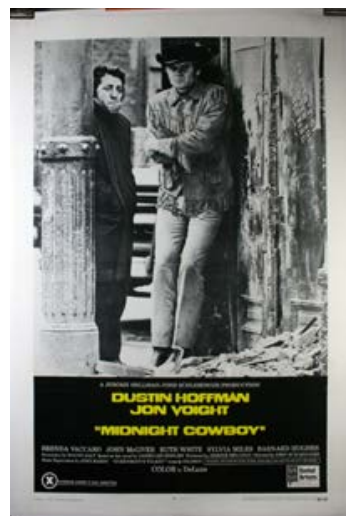

Figura 8-Cartaz original de "Midnight Cowboy"

Fonte:

www.movieart.com

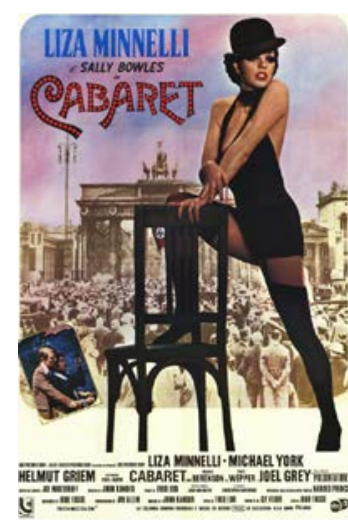

Figura 9 - Cartaz original de "Cabaret" Fonte: www.movieart.com

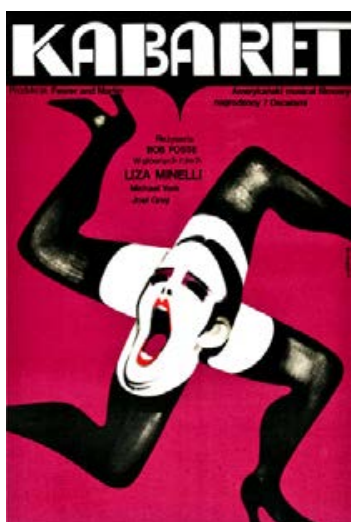

Figura 10 - Wiktor

Gorka, Cartaz de "Cabaret", 1973.

Fonte: MEGGS, 2009

cartazes eram o único elemento colorido nas cercas cinzas. Havia ainda quadra inteiras de ruínas cercadas por cercas de madeira, e estes foram as primeiras galerias de cartazes". Assim, trabalhando dentro de um sistema artístico totalmente subsidiado pelo governo, os designers poloneses assumiram uma posição importante na reconstrução da cultura do país (CZESTOCHOWSKI; FIJALKOWSKA, 1978, p. 4, tradução nossa). "O cartaz passou a ser fonte de grande orgulho nacional na Polônia; seu papel na vida cultural do país é único" (MEGGS, 2009, p. 548-549).

A estética do cartaz polonês é extremamente variada, visto que cada artista tomou uma direção particular. Tanto que, após meados dos anos 1950, a denominação "Escola Polonesa" caiu em desuso em favor da abordagem individual de cada artista. (CZESTOCHOWSKI; FIJALKOWSKA, 1978, p. 4, tradução nossa)

É possível, no entanto, observar alguns princípios norteadores no trabalho dos artistas, em especial nos cartazes das décadas de 1950 e 1960. Destaca-se o uso de pintura de cores vibrantes e fortes qualidades gráficas. Os temas eram geralmente enigmáticos e intrigantes, já que os artistas eram encorajados a interpretar a realidade de maneira metafórica ou simbólica ao invés de literal (THOMAS et al., 2001, p. 4).

Os designs consistiam em ilustrações pintadas e letras desenhadas. As vezes, exibiam um realismo simples e direto: outras vezes, eram decorativos ou então dramáticos, freqüentemente apresentando elementos surrealistas: e outras vezes oníricos, não raro lembrando pesadelos (HOLLIS, 2000, p. 186).

O poder de atração dos cartazes poloneses está relacionado com sua originalidade e com a capacidade dos artistas de construir símbolos concisos, já que o cartaz era "uma revisão artística" e "uma busca de um símbolo apropriado" para representação do filme (ZIELINSKI, 1994, p. 36, tradução nossa). É perceptível a influência dos movimentos modernistas, ainda que os vestígios da cultura nacional sejam dominantes. "Apresentando traços de sua cultura folclórica, esse estilo nacional recebeu certa influência de Cassandre" (HOLLIS, 2000, p. 185).

De acordo com Meggs (2009, p. 549), os cartazes de Tomaszewski frequentemente utilizavam colagens. $O$ artista criava projetos a partir de pedaços de papel colorido rasgado e cortado, e em seguida impressos em serigrafia. Świerzy, por 
outro lado, abordava o design gráfico de um ponto de vista pictórico, e utilizava uma ampla variedade de materiais como acrílico, lápis e aquarela (MEGGS, 2009, p. 553).

Zielinski (1994, p. 36) aproxima os cartazes poloneses à corrente minimalista sintetizada na máxima "less is more" de Mies Van Der Rohe. Para o autor, um dos principais princípios da escola polonesa era "the less, the more". Projetar um cartaz significava pensar em vez de desenhar, ou seja, buscar a expressão visual para uma ideia. "Parece que a regra quanto menos, mais, juntamente com as realizações de destaque de Tadeusz Trepkowski e Henryk Tomaszewski, deu origem à ilustre carreira e alta posição alcançada pelo cartaz polonês" (ZIELINSKI, 1994, p. 36, tradução nossa).

Em 1966 foi organizada na Polônia a 1a Bienal do Cartaz e dois anos depois foi fundado o primeiro Museu de Cartazes do mundo no Palácio Wilanów, em Varsóvia (THOMAS et al., 2001, p. 9). De acordo com Meggs (2009, p. 549) foi devido a isto que "o cartaz polonês passou a receber atenção internacional durante os anos 1950". Zielinski (1994, p. 37, tradução nossa) observa que foi uma grande surpresa para o Ocidente descobrir na Polônia pós-stalinista realizações artísticas "do mais alto nível de originalidade". Na abertura do livro publicado como resultado de uma exposição de cartazes poloneses realizada em 1978 em Baltimore, o presidente da instituição afirmava: "Em si mesmos, esses cartazes poloneses são exemplos impressionantes de comunicação visual. $E$, sendo praticamente desconhecidos neste país, eles serão uma revelação para a maioria dos espectadores" (CZESTOCHOWSKI; FIJALKOWSKA, 1978, p. 2, tradução nossa).

O período entre os anos 50 e 60 representou o auge do cartaz polonês. Outras correntes tiveram sequência nos anos 70 , mas quando o sistema comunista teve fim no final da década de 80 a produção de cartazes patrocinados pelo governo também cessou. Grandes agências entraram na polônia e a propaganda no estilo norte americano se tornou corrente e dominante (ZIELINSKI, 1994, p. 29).

O cartaz polonês permanece sendo relevante nos dias atuais, mas na condição de objeto de coleção. Para Zielinski (1994, p. 38), o cartaz como objeto comercial não só mudou a atitude dos artistas, mas também o próprio cartaz. Para o autor, esta produção "comercial" reduziu o interesse do público pelo cartaz polonês.

\subsection{Saul Bass}

Os movimentos modernos que influenciaram desde muito cedo as artes aplicadas na Europa, como foi o caso da Polônia, demoraram um pouco para adentrar nos Estados Unidos. Foi apenas durante a Primeira Guerra Mundial que o cartaz passou a ser amplamente utilizado como meio de comunicação. Após a Segunda Guerra o país consolidou-se como potência mundial e adentrou em um período de pleno desenvolvimento econômico e expansão da produção e do consumo.

Uma das primeiras e mais importantes correntes do design moderno norte americano foi a Escola de Nova Iorque, cujo principal expoente foi o designer Paul Rand. Ele exerceu enorme influência no design da metade do século 20 e introduziu a arte e o design modernos da Europa na arte comercial norte americana. Perto do fim da década de 1940, Rand havia elaborado um vocabulário inovador de design gráfico baseado na forma pura. Em meados dos anos 50 alterou completamente a maneira pela qual as grandes corporações usavam a identidade visual. 
A cultura corporativa incipiente reconheceu no design funcionalista atrativos irresistíveis como austeridade, precisão, neutralidade, disciplina, ordem, estabilidade e um senso inquestionável de modernidade, todas as qualidades que qualquer empresa multinacional desejava transmitir para os clientes e funcionários" (CARDOSO, 2004, p. 154).

Rand era um dos grandes ídolos de um jovem designer chamado Saul Bass, filho de um imigrante judeu. Interessado desde jovem pela vanguarda europeia, inspirou-se também em Moholy-Nagy e Cassandre para desenvolver uma linguagem própria, que Ihe rendeu um lugar importante na história do design (BASS; KIRKHAM, 2011 p. 9).

Uma das grandes figuras do design moderno americano, Bass desenvolveu extensa carreira profissional atuando em diferentes áreas do design (BASS; KIRKHAM, 2011 p. XIII). A produção de cartazes de filmes representa uma parte importante do seu trabalho, ainda que sua reputação internacional como designer tenha se estabelecido em razão das aberturas de filmes (BASS; KIRKHAM, 2011 p. 107).

Bass estudou e trabalhou em Nova lorque no início da sua carreira, e mudou-se para a Califórnia na década de 1950 para trabalhar na indústria do cinema. Para Meggs (2009, p. 494), "as sensibilidades da Escola de Nova York foram levadas para Los Angeles por Saul Bass". Seu primeiro trabalho em Hollywood foi como "layout-man" na Twentieth Century-Fox (BASS; KIRKHAM, 2011 p. 8). No entanto, Bass enfrentou dificuldades para implantar uma linguagem inovadora em seu trabalho dadas as restrições impostas pelas necessidades comerciais de divulgação dos filmes. "O cinema desde muito vinha usando para a promoção de filmes retratos tradicionais de atores e atrizes e tipografia medíocre e extravagante nos e títulos" (MEGGS, 2009, p. 494).

Saul queria produzir arte, mas havia pouco espaço para a criatividade na publicidade comercial de um filme. Ele chamava a abordagem do design corrente de "Veja, Veja, Veja: Veja os missionários cozidos vivos! Veja as virgens dançarem no Temple of doom! Veja o Krakatoa explodir!" (BASS; KIRKHAM, 2011 p. 6, tradução nossa). De fato, os estúdios de cinema eram relutantes em arriscar suas campanhas de marketing com estratégias mais arrojadas, em razão das altas cifras em jogo no lançamento de um filme (BASS; KIRKHAM, 2011 p. 107).

Dois anos depois de chegar à California, Bass abriu seu próprio escritório. Em 1955 realizou seu primeiro trabalho para o filme The man with the golden arm, de Otto Preminger. Apesar da resistência do estúdio, Preminger concedeu ao designer liberdade criativa. O resultado foi uma revolução na forma de se divulgar um filme, a partir da proposta de um sistema completo de identidade visual para sua promoção.

\footnotetext{
Por volta de 1958, para um filme típico, Saul oferecia os estúdios não só as telas de abertura, mas também uma marca, trailer para TV, cartazes (em quatro tamanhos), anúncios comerciais (até seis por filme), anúncios de jornal (até a vinte por filme), capa de álbum e cartão do metrô de Nova York (BASS; KIRKHAM, 2011 p. 107, tradução nossa).
}

No quesito estético, Bass rompeu completamente o padrão corrente neste projeto. Para esse filme sobre dependência química, o designer criou um símbolo singular, composto por "um espesso braço pictográfico lançando-se para baixo em um retângulo composto de barras em forma de tijolos que enquadra o título do filme" (Fig. 13) (MEGGS, 2009, p. 495). O símbolo estava no centro de uma campanha publicitária unificada e global sem precedentes no cinema mundial. Os anúncios "quebraram as regras do que uma campanha deve fazer, porque eles se concentraram em uma coisa: o braço" (BASS; KIRKHAM, 2011 p. 120, tradução nossa). Ainda segundo o autor, era 
uma proposta extremamente metafórica, decorrente da ambição de criar gráficos que anunciam um filme ao invés de vendê-lo.

Apesar de a maioria dos estúdios pensar que era loucura para fazer propaganda de um filme com tal imagem redutora, foi exatamente esta ruptura que tornou Bass o reconhecido mestre do design filmes, abrindo-lhe a oportunidade de criar para os filmes de Otto Preminger Anatomy of a murder (1959); de Alfred Hitchcock Vertigo (1959), Psycho (1960) e The birds (1963) (Fig. 14); entre outros.

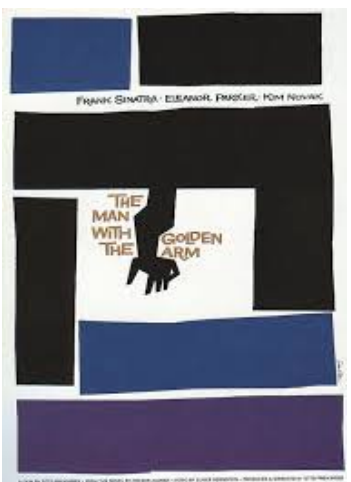

Figura 12 - Saul Bass, Cartaz de "The man with the golden arm", 1955. Fonte: BASS; KIRKHAM, 2011

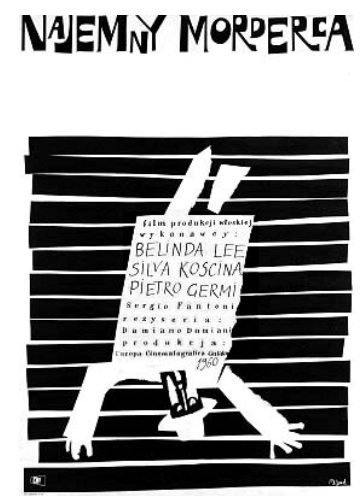

Figura 13 - Jerzy Flisak, cartaz de "The Hitman" 1962

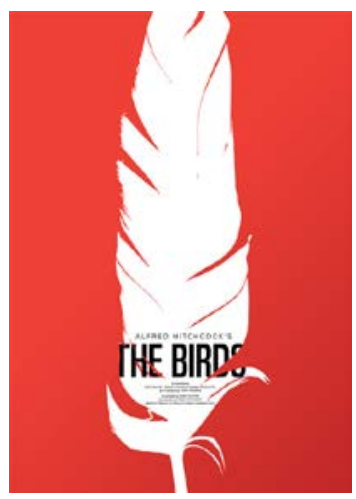

Figura 14 - Saul Bass, Cartaz de "The Birds", 1963. Fonte: BASS; KIRKHAM, 2011

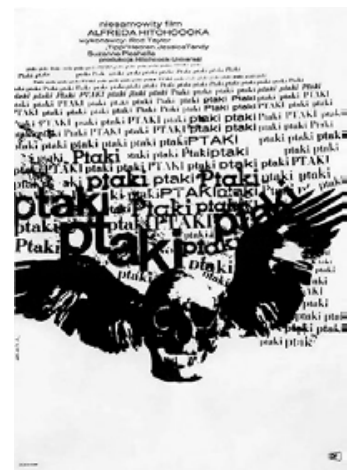

Figura 15 - Bronislaw Zelek, cartaz de "The Birds", 1965. Fonte: www.polishposter.com

A forma e equilíbrio assimétricos de Rand foram uma forte referência para Bass, porém, sua estética é única. De acordo com Meggs (2009, p. 494), "enquanto as composições cuidadosamente orquestradas de Rand usavam contrastes complexos de forma, cor e textura, Bass em geral reduzia seus projetos a uma única imagem dominante" (BASS; KIRKHAM, 2011, p. XIV, tradução nossa). Ainda segundo os autores, era notável sua capacidade de chegar ao cerne de um problema de design e traduzi-lo em ícones visuais simples e convincentes.

Ainda que tenha utilizado ampla gama de referências visuais e culturais em sua busca para resolver os problemas individuais de cada trabalho, é possível apontar elementos recorrentes na estética de Bass. É evidente a tendência para a redução, economia e minimalismo associados aos movimentos modernos, bem como o interesse pela fragmentação, ambiguidade e metáfora que estavam muito em evidência na década de 1950 (BASS; KIRKHAM, 2011, p. XV).

Para Meggs (2009, p. 496) "a simplicidade e a objetividade do trabalho de Bass permitem ao espectador interpretar imediatamente o conteúdo". Saul costumava dizer que "buscava uma ideia simples", mas na verdade ele era mestre em criar formas simples que expressavam ideias complexas, que "ofereceriam ao público um conjunto de pistas, uma espécie de chave hermenêutica para significados mais profundos sob a superfície do filme (BASS; KIRKHAM, 2011 p. 107, tradução nossa).

Embora ele reduzisse as mensagens a simples imagens pictográficas, seu trabalho não se parece com a gráfica elementar do construtivismo. Formas irregulares são cortadas em papel com tesoura ou traçadas com pincel. Traçadas livremente, letras decorativas são frequentemente combinadas com tipografia ou caligrafia. Existe uma energia robusta em suas formas e uma qualidade quase casual em sua execução. Embora as imagens sejam 
simplificadas a uma expressão mínima, falta-lhes a exatidão da medida ou construção que poderia torná-las rígidas (MEGGS, 2009, p. 494).

Os cartazes e as aberturas de Bass representaram uma importante ruptura na forma como a indústria norte americana divulgava seus filmes. O designer foi pioneiro em promover aproximações entre o design e o cinema. Ao longo de sua extensa carreira, Bass desenvolveu trabalhos em outras áreas comerciais e ficou conhecido também por suas identidades visuais.

\section{CONCLUSÃO}

Por meio desta pesquisa, dedicada aos aspectos contextuais e estéticos dos cartazes da Escola Polonesa e de Saul Bass, ficou ainda mais evidente a relevância de ambos no que diz respeito à implantação de uma nova linguagem de cartaz de cinema. Nos dois casos, os designers deliberadamente buscavam romper com as tradições visuais existentes e marcaram a história do design internacional por suas iniciativas.

No aspecto estético, muitas aproximações podem ser realizadas. Tanto os cartazes poloneses quanto os criados por Bass tiveram referências em comum, enraizadas nos movimentos modernos europeus e em especial na linguagem de formas puras preconizada por Cassandre. Em ambos desenvolveu-se um vocabulário visual essencialmente gráfico, apoiado em grandes planos de cores chapadas, uso de técnicas variadas como colagem, recortes e tipografia feita à mão. Mesmo a geometria se assemelha em alguns projetos (Fig. 12 e 13), bem como os estilos em quais foram enquadrados: tanto Bass quanto alguns artistas poloneses foram rotulados como minimalistas em razão de suas formas mínimas e altamente expressivas.

A substituição da imagem figurativa em favor da imagem conceitual apoiada na metáfora, que visava ativar no espectador outros níveis de compreensão sobre o filme, também é um forte ponto em comum. É especialmente enriquecedor observar os filmes que tiveram cartazes feitos tanto por Bass quanto por artistas poloneses (Fig. 14 e 15), pois constituem exemplos claros das suas semelhantes estéticas e conceituais.

Por outro lado, as diferenças também são evidentes. Ainda que muitos dos cartazes da Escola Polonesa e de Saul Bass tenham sido criados basicamente na mesma época e compartilhem a estética de ruptura dos códigos visuais estabelecidos, os contextos de produção e motivações de seus autores são completamente distintos.

De um lado, uma sociedade sedenta por expressar sua identidade nacional e totalmente livre das exigências comerciais, eleva o cartaz ao status de obra de arte contando com o subsídio das instituições estatais. De outro, um designer em busca de reconhecimento na competitiva sociedade norte-americana, reinventa o design como ferramenta de venda no contexto da indústria do cinema e conquista reputação internacional trabalhando com os grandes diretores de Hollywood.

No contexto polonês, o cartaz era a forma mais viável de comunicação de massa, visto que outros meios não dispunham do mesmo alcance. Na sociedade norte americana, pelo contrário, o cartaz desenvolveu-se como parte de um sistema mais abrangente que incluía outras peças de comunicação impressas e audiovisuais. No mesmo sentido, os artistas poloneses se especializaram na arte do cartaz, enquanto Bass desenvolveu um legado multidisciplinar.

Os paradoxos que brotam desta aproximação nos motivam a investigar com mais profundidade as obras, autores e contextos. Novas conclusões podem surgir a partir de uma análise mais minuciosa de cartazes específicos que tenham sido criados 
para o mesmo filme ou que apresentem soluções visuais semelhantes. Parece importante e necessário investigar, ainda, influências mútuas que possam ter havido entre os artistas poloneses e o designer norte americano. Por fim, acredita-se que tanto esta pesquisa quanto seu aprofundamento podem contribuir com o estudo do design ao oferecer uma aproximação à gênese de linguagens de vanguarda.

\section{REFERÊNCIAS}

AUSTONI, Andrea. The legacy of Polish Poster Design. Smashing Magazine.

17/01/2010. Disponível na internet por http em:

<https://www.smashingmagazine.com/2010/01/the-legacy-of-polish-poster-design/>.

Acesso em: 01/04/2016.

BASS, Jennifer; KIRKHAM, Pat. Saul Bass: a Life in film \& design. London: Laurence King Publishing, 2011.

Behind the Poster (2010) Título original: Druga Strona Plakatu. Direção de Marcin Latatto. Polônia. (52 min). Disponível na internet por http em:

<https://vimeo.com/channels/latallodocs/50977573>. Acesso em: 01/04/2016

CARDOSO, Rafael. Uma introdução à história do design. 2. ed. rev. e ampl. São Paulo: Edgard Blücher, 2004.

CZESTOCHOWSKI, Joseph S.; FIJALKOWSKA, Janina. Poster Art in Poland: 1899-1978. Baltimore: The Maryland Institute College of Art, 1978.

Freedom on the Fence (2012). Direção de Andrea Marks e Glenn Holsten. Estados Unidos. (39 min). Disponível na internet por http em: <https://www.indiereign.com/v/483c9>. Acesso em: 01/04/2016

HOLLIS, Richard. Design gráfico: uma história concisa. São Paulo: Martins Fontes, 2000. MEGGS, Philip B. História do Design Gráfico. Tradução: Cid Knipel. São Paulo: Cosac Naify, 2009.

MILLIE, Elena; KANTOROSINSKI, Zbigniew. The Polish Poster: From Young Poland through the Second World War. Washington, D.C.: Library of Congress, 1993

MOLES, Abraham Antoine. 0 cartaz. São Paulo: Perspectiva, 2004.

MONZANI, J. M. A. S. Cinema e Design Gráfico: Correlações - Inglaterra nos anos 70. www.mnemocine.com.br, São Paulo, SP, v. 16, p. 30, 2006.

THOMAS, V. et al. The Polish School of Poster Art: Posters From the University of Northampton's Osborne Robinson Collection. Online: The University of Northampton, 2011. Disponível na internet por http em: <http://www.blurb.com/books/2356310the-polish-school-of-poster-art>. Acesso em 01/04/2016.

VALENTE, Francisco. O olho vivo de Saul Bass. Portal Ípsilon. 13/04/2012. Disponível na internet por http em: <http://ipsilon. publico.pt/cinema/texto.aspx?id=303361>. Acesso em: 10/09/2013

ZIELINSKI, Florian. The rise and fall of governmental patronage of art: A sociologist's case study of the polish poster between 1945 and 1990. International Sociology. vol. 9, n. 1, p. 29-41,1994. 